\title{
A Study on Teaching Practice-Led Research into Ready-Made Intervene Design in Metalsmithing Education
}

\author{
I-Ting Wang1, Chien-Chih $\mathrm{Ni}^{2}$, Rungtai Lin ${ }^{3 *}$ \\ ${ }^{1}$ Department of Crafts and Design, Nation Taiwan University of Arts, Taiwan \\ ${ }^{2}$ Department of Fashion Design, Hsuan Chuang University, Taiwan \\ ${ }^{3}$ Graduate School of Creative Industry Design, National Taiwan University of Arts, Taiwan \\ Email: etinw@ntua.edu.tw, nancyni1008@gmail.com, ${ }^{\star}$ rtlin@mail.ntua.edu.tw
}

How to cite this paper: Wang, I.-T., Ni, C.-C., \& Lin, R. (2022). A Study on Teaching Practice-Led Research into Ready-Made Intervene Design in Metalsmithing Education. Creative Education, 13, 504-525. https://doi.org/10.4236/ce.2022.132030

Received: January 3, 2022

Accepted: February 14, 2022

Published: February 17, 2022

Copyright ( 2022 by author(s) and Scientific Research Publishing Inc. This work is licensed under the Creative Commons Attribution International License (CC BY 4.0).

http://creativecommons.org/licenses/by/4.0/ (c) (i) Open Access

\begin{abstract}
The cultivation of design talents involves fostering not only basic design ability through design education, but also the ability to solve complex problems, reflect and innovate. The content of traditional metalsmithing courses is mainly based on technical practice. This course intends to enhance students' design thinking by prompting a metalwork design through ready-made objects to flip inertial and encourage out-of-the-box design thinking. The purpose of this research is to see how ready-made objects as a media could intervene in educational practice to stimulate students' creative thinking and strengthen their "4I" abilities: Imagination, Insight, Ideation, and Identification. Further, applying the Double Diamond model as a teaching framework to guide students' innovative thinking and imagination training in the learning process, this research conducts qualitative data analysis through teaching observation, learning process, feedback reflection, interview data, and work achievement. The results show that the ready-made object intervention in educational practice does help students form a contextual design and present multi-faceted creative results.
\end{abstract}

\section{Keywords}

Ready-Made, Metalsmithing Education, Design Practice, Creative Design Thinking

\section{Introduction}

The purpose of design education should consider designers that meet the new form while taking into consideration the global trend and the needs of future 
talents. Brown (2008), the CEO of a renowned design company, IDEO, said that future talents should be able to solve complex problems and possess reflective, autonomous cross-domain knowledge in addition to basic design capabilities. Scholars have discussed the importance of innovative teaching strategies, emphasizing the use of flipped classrooms and gamification to lead the curriculum. They further stressed that diversified teaching methods and situations could effectively improve students' learning focus and effectiveness (Zamora-Polo et al., 2019).

In design education, metalsmithing is a course based on technical practice, positioned at the intersection of art, design, and craft. The development of metalsmithing education in Taiwan did not begin until talents in the field of metalsmithing with western educational backgrounds were introduced to serve at universities and colleges after 1985. Gradually, departments and courses related to metalsmithing education were established. At universities and colleges, juniors are quite prepared in terms of technical learning. However, training for creative thinking within a limited classroom setup is a major challenge and an urgent concern for teachers that needs a solution.

Art and design continue to explore practice-led research on the creation of awareness and creativity, an important foundation for design education (Freitas, 2007; Ho, Lee, \& Wang, 2013). Vande Zande (2007) suggested that while design thinking is a method for solving creative problems, students can learn teamwork skills, define problems, and generate solutions by connecting action with thinking. Cropley \& Cropley (2008) pointed out that creative performance attaches importance to four aspects: learning motivation, thinking skills, knowledge experience, and personality traits. In particular, it emphasizes learning motivation and personality traits as the most important aspects. Therefore, through creative thinking training, learners' self-awareness, meaning interpretation, and critical reflection can promote the process of constructing self-core competence and realization.

Applying the Double Diamond model as a teaching framework, this study starts from unstructured and open-ended questions, using Ready-Made as a question or a stimulus. To value the design of learning situation at four stages, creative design thinking training intervention in metalsmithing courses is developed with the teacher as the guiding role. It is worth studying whether it can improve students' creative thinking and transfer it from a linear to a multi-dimensional creative thinking process. The purpose of this research is two-fold:

1) To evaluate whether the use of Ready-Made as a stimulus for design helps students improve their creative practice.

2) To discuss the grounds that lead students to multi-dimensional thinking.

\section{Literature Review}

\subsection{Imagination and Creativity in Design Education}

The Shorter Oxford Dictionary defines "imagination" as "the mental considera- 
tion of actions and events not yet in existence; scheming or devising; a fanciful project; the power which the mind has of forming concepts beyond those derived from external objects." (Collins \& Stevenson, 2004). On the other hand, Merriam-Webster dictionary defines imagination as "the act or power of forming a mental image of something not present to the senses or never wholly perceived in reality" (Woolley, Bunce, \& Boerger, 2020). Imagination is also often assigned a key role in the development of creative thought (Hoff, 2013). As creative thinking is one of the cores of future education and learning, a deep understanding of this field is necessary to discover problems and establish the relationship between motivation and social-emotional cognition (Chen \& He, 2013).

Furthermore, creativity is a general ability that can be applied across problem domains to explore the essence of things through critical debates (Baer, 2021; Plucker, 1998) and make what does not exist today possible in the future (Rosen, Stoeffler, \& Simmering, 2020). Through the interaction between teaching and learning, the application of design thinking methods is emphasized, including imagination and experience, text and logic, creativity, and critical thinking. Abstract thinking in design practice to guide students to integrate problem awareness, material analysis, formal (configuration) understanding, design discovery, thinking methods, and other phased problem-solving training, further-more the emotion involved (Bi, Lyu, Cao, \& Lin, 2021). In this way, different purposes in creative thinking are created and realized by shifting from perceiving objects to understanding knowledge.

Creativity is often measured by divergent thinking tasks that assess both the ability to generate ideas and generate novel ideas (Runco \& Acar, 2021). Walker connects the development relationship between art and science based on the concept of the design tree (Wu, Su, \& Tsau, 2013). Training or inspiring imagination is a significant part of design education, which transforms imagination into specific visualized images or objects; that is, a topic of teaching practice in basic design education. Vygotsky (2003) mentioned that the element constituting imagination is listening to others' experiences; that is, social experience, which is a conscious, game-like thinking process. Based on other people's experiences, we can imagine the unknown experience, enrich the memories and inspire more possibilities. Hence, imagination is the foundation of creativity in design education, while creativity carries out contextual integration and thinking when future designers face challenges. Moreover, creativity is based on an alternating creative process of insight and analytical thinking (Zedelius \& Schooler, 2016).

Lubart (2021) pointed out that creativity can encourage people to think outside the box and produce novel and useful ideas in different fields. In this way, the dead lock can be overcome, improving problem-solving ability. The association theory of creativity implies the relationship between abstraction and creativity. Importantly, there may be a continuous interaction cycle between the generation and the exploration stages until the creative results are constructed 
(Cropley, 2006).

\subsection{Employing the Double Diamond Model into Practice-Led Research}

The core of practice-led research is practice, aimed at studying problems formed between the practice and the practitioner through the methodology of a practitioner (Gray, 1996; Haseman, 2007; Ho et al., 2013). Ho et al. (2013) emphasized that the process of practice-led research is suitable for creative teaching in colleges and universities, which can help students transform artistic creation into self-awareness. She also pointed out that teachers must provide a model that guides teaching based on the above-mentioned model and specific creative problem-solving process given the lack of studies on students.

Practice-led research is composed of three parts, namely, "artist/practitioner", "the creative product", and the "critical process". Any part can initiate the research and form an interdependent relationship in the practice-led research framework. Furthermore, practice (creation) is the core role of knowledge creation, while practice-led research is supported by "critical reflection and reflective action" (Sullivan, 2009).

Practice-led research generates knowledge through practical processes and certainly verifies such knowledge through critical reflective actions. Torp and Sage (1998) proposed that from the perspective of constructivism, learners construct their own knowledge system in the experiential (hands-on, brain-based) process and construct a way of self-learning through dialogue, assistance, and interaction with teachers and peers. Learners also organize and construct impressions that form their own cognition according to their personal feelings and cognition, which can deepen the importance of designers' role in self-assessment and reflection pointed out that the development of experimental learning methods is receiving attention. They also stressed that the student-centered learning method should be adopted, and the training of creative and critical thinking skills should be emphasized to effectively improve the quality of learning (Habib, Nagata, \& Watanabe, 2021).

Practice-led research attaches importance to the creative process, where teachers can guide students to construct creative thinking in the creative process through systematic teaching. The Double Diamond model was proposed by the British Design Council in 2005, mainly consisting of two phases of thinking: divergence and convergence. While the first phase explores (diffuse) and defines (converge) problems, the second phase develops (diffuse) and solves (converge) problems and further expands the classified knowledge into a creative phenomenon by reconstructing concepts (Ward, Smith, \& Vaid, 1997).

\subsection{Ready-Made Intervenes into Design Practice}

The concept of Ready-Made means "pre-made" or "ready-made item" in the English dictionary (Lu, 1996; Lin, Lin, \& Wang, 2019). In the field of art, the 
concept is more important than the form of thinking, which operates a kind of conscious expression that enables one to get rid of the traditional framework. It is a most famous noun in artistic techniques, and Marcel Du-champ (18871968), the pioneer of Dadaism, is the first artist to use Ready-Made for creation. A classic example is a sculpture named "Bicycle Wheel" when he inserted the wheel fork of an old bicycle's front wheel upside down into the stool in 1913. Another famous work of his, called "Fountain", is a urinal upside down, signed with R. Mutt. He deliberately chose ordinary objects as materials, which overwhelmed the inevitability that artworks must be created by the artist himself (Wolfram, 1992).

Since the 1930s, surrealist artists transfigured commonplace objects as part of artworks and inspired conceptual design. Ready-made has been one of the methods involved in the unruly design, which bloomed so many design products. Hekkert, Snelders, \& Van Wieringen (2003) demonstrated that both typicality and novelty products are jointly and equally effective in explaining the aesthetic preference of consumer products. Therefore, the use of everyday products is attributed when designing emotionally involving products. Lee (2005) stated that in industrial design, using or designing Ready-Made as a unit component or a part of the main body is closely related to the daily practical use in the design of products that conform to or constitute aesthetics and functions. The transformation of the design concept is affected by Italian brothers, the Castiglionis, in the 1950s, which transformed traditional materials and technologies through the thinking of the new era, beginning a new reform.

The field of crafts emphasizes the possibility of cross-domain integration between experiments and the value of crafts. Hu (2013) explored the expression of "Ready-Made" in contemporary jewelry and indicated that its formal languages, such as its narrative, temporal, symbolic, and story nature, can enrich metal jewelry, including its ways of expression like narrative, exaggeration, deviation, allegorical association, and symbolic ideology, which all become a bridge between the creator and the viewer, promoting the development of the modern forms of jewelry.

Ready-Made is a medium between practice and design thinking in which the design is with-out intuition. Through the metamodel from the design process, the wild imagination of objects is unleashed. According to Eggink's five rules, it can be seen that trans-forming ready-made objects can improve designers' interest concerning emotional response and aesthetic preference thinking (Eggink, 2010). It is about giving form to an abstract de-sign idea, or in other words, the materialization of a design concept (Eggink, 2018). Vygotsky (2003) also pointed out that art and design require the collaboration of imagination and thinking, as well as the conscious thinking process. There should be an inner performance during the process-for instance, a children's game. As a result, we should express different levels of subjects through borrowing, continuing, and translating objects and extend the intuitions of materials in the field of crafts through ma- 
nual labor.

\section{The Theoretical Framework and Methods}

This research adopted a qualitative method, case analysis, and practice-led research to explore the double diamond model through the Ready-Made Intervene Design in metalsmithing education to form a teaching framework, Design Council identified four phases in a design process which are discover, define, develop, and deliver; further extended the double diamond model to new double diamond model: framework for innovation and indicated that for innovation, designer needs a process for design, and it is not a liner process (Dennis, 2019; Rafiq, 2021; Design Council). Under the new double diamond model, visual thinking and co-creation are good help for inspiring new ideas (Dennis, 2019). As show in Figure 1 to conduct design thinking, share discussions on research planning, teaching process, problem awareness, and teaching results, and explain the research participants, the teaching field, and the data collection and analysis.

\subsection{Research Participants}

This research studies the juniors majoring in metalsmithing at a certain national university. The course "Metalsmithing Workshop D" lasted one semester with a total of 18 weeks of classes and 3 hours per week. A total of 24 students who have finished two years of metalsmithing courses were enrolled in this class.

The researcher started from the technology-based course different from the past, to stimulate students' creative thinking and imagination, change the role of researchers as leaders, center learning on students, and promote practical experiences like self-understanding, design ideas, drafting concepts, media experimentation, technology integration through self-study in order to complete the creation and publication.

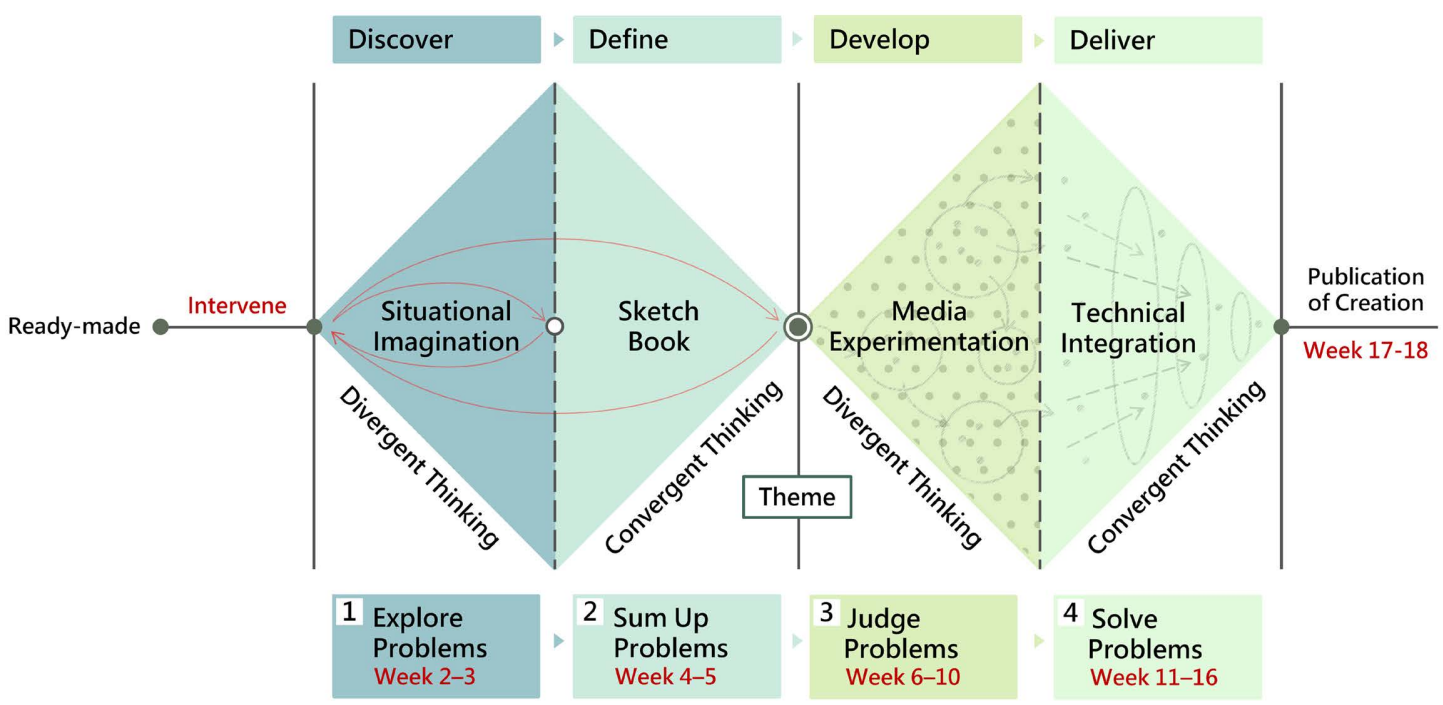

Figure 1. Teaching framework formed by Ready-Made Intervene Design Thinking (prepared by the researcher). 


\subsection{Teaching Field}

This study mainly involves the practice classrooms for metal workshops in the Department of Crafts and Design. Students should present designs at different sites and perform group meetings and discussions in the classroom for theoretical education multiple times. In class, students are encouraged to practice their conceptual thinking and creativity. For extracurricular activities, assistance and guidance in the context were provided, and students were encouraged to think out of the box through the sketchbook, record creative reflection, perform experiments, and conduct creation analysis.

\subsection{Instructional Design}

Combining the above-mentioned literature and teaching framework, this research bases on the four stages of the Double Diamond Model to carry out the design of the teaching unit and the planning of teaching contents, as shown in Table 1. In terms of the teaching design, starting from a game-like method, it is planned to choose a Ready-Made for someone and send it by mail. Students can specify a receiver and propose a question or send them the sample randomly. The roles of the teacher, as a coach, include 1) exploration: to depict 4 comic strips by caricature, describe through imagining the situation, and describe how

Table 1. Teaching unit planning.

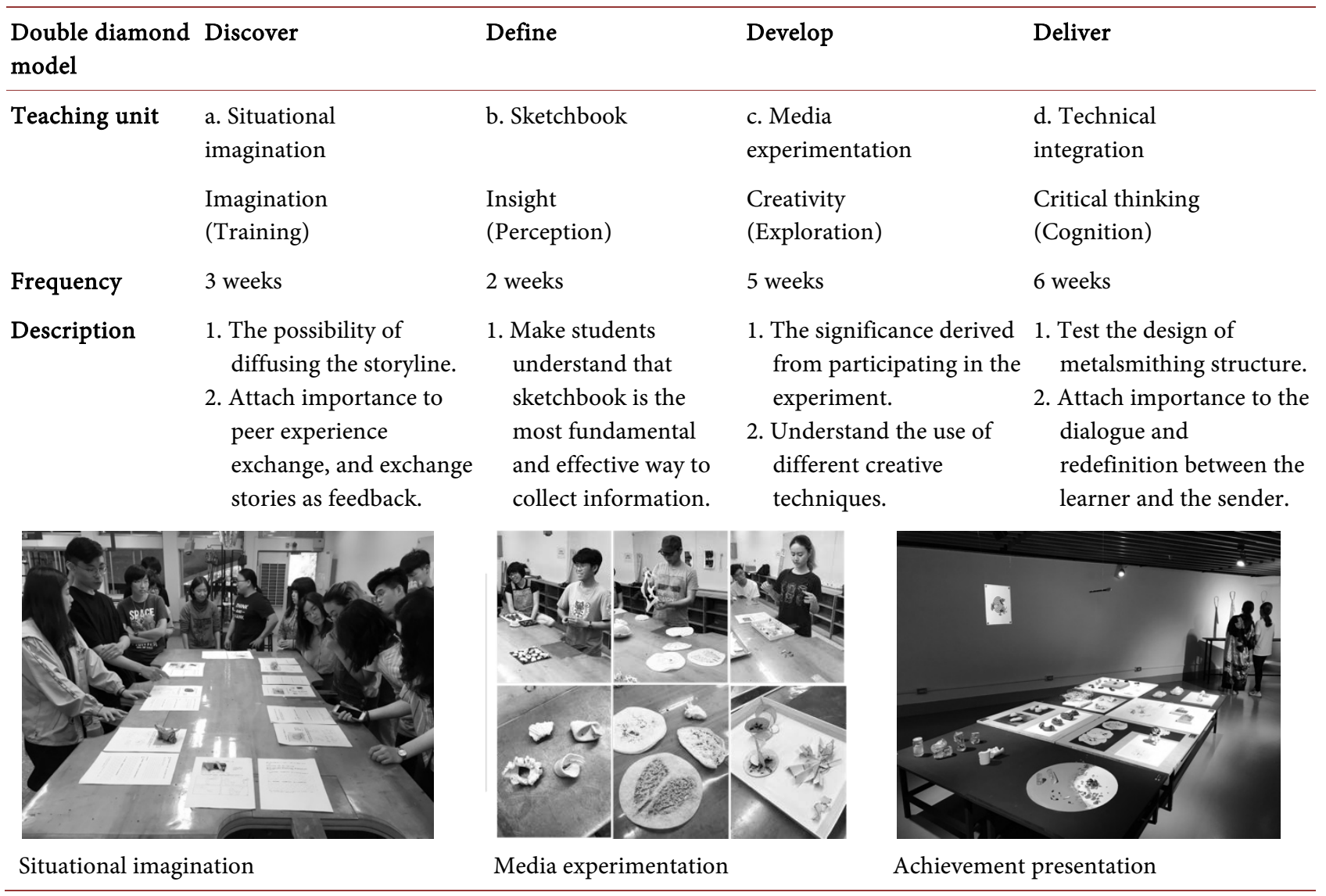


the "object" drifts to you; 2) define: to define your situational story of the Ready-Made, ask the other party about the story through group discussions, ex-change the story with a certain classmate, and present a different story as feedback; 3) develop: through the theme and the material experiments, students can use the core value and conceptual imagination as the key node to trigger the viewpoint that "develops" the way of thinking and the transformation of design in media experimentation; 4) deliver: to borrow group exchange opinions, interrogations, and collective evaluations, re-turn to the results of the above-mentioned three stages before the convergence, and develop a series of products by integrating craft making techniques. Through the above-mentioned four stages-in the second divergent thinking and the second convergent thinking, starting from the delivery of the object to the focus of the theme-students should draft the design and implementation plan, re-explore and converge in the media experimentation, conduct teacher observation and design evaluation in the teaching practice, and perform effective peer feedback, course evaluation, and reflective feedback.

\subsection{Implementation Method and Data Collection}

This study focuses on student-centered teaching and learning-a creation design learning model promoted by Ready-Made. The problem awareness stems from the teacher's experience and their perception that students often lack methods and dialogues to learn creative connections in the creative process. Through the $4 \mathrm{D}$ (discover, define, develop, and deliver), media, flowchart planning, and implementation methods are built to in-spire and guide creative thinking, namely situational imagination, sketchbook, media experimentation, and technology integration.

Foundation education related to design education provides thinking and feedback of different experiences through " 4 comic strips" and "exchanges of stories" and gives scores and exchanges opinions through peer review. "Sketchbook" refers to learning deconstruction and construction through data collection in the creation process, allowing students to understand the importance of sketchbooks to integrating design context. "Media experimentation" is based on phased questions through tactile media experimentation to develop a multi-dimensional design prototype. During the process, importance should be attached to peer opinions, group discussions, idea narration, and independent publication in order to evaluate how the final work should interact with the public and invite field experts to critique on the works. By the end of the study, effective reflections and feedback on the course should be provided through questionnaire surveys, after-class criticisms, and individual interviews during the two-week exhibition.

\section{Data Collection and Coding}

The resource analysis of this research is qualitative, which involves teacher observations, discussions (individual and group), interviews (individual), data 
analysis during the creative process (text and sketchbook), and metalsmithing works. The student questionnaires and interviews include context discussion, problem-solving, reflections, and research on the creation. The in-text data and coding numbers are Q for Questionnaire, D for Discussion, I for Interview, O for Operation, $S$ for student (S01-S23). In addition, there are S- to the code of the materials. For example, S03-1 refers to the recording of the interview of Student 03 , and S4-Q refers to the student questionnaire. The data analysis mostly used textual description and teacher observations as the research results, a part of which were digital, corresponding to the questionnaire results. The semi-structured interviews were scheduled to be carried out after the exhibition, which lasted one hour for each interviewee. The interviews were based on the outlines predetermined by the researcher. Further, the content of the interviews was made into a verbatim manuscript, organized systematically. Based on multiple data collection and sources, meaning encoding was carried out to establish research validity through cross-analysis between questions and data.

\section{Results and Discussion}

\subsection{The Intervention of Ready-Made Inspires Design Motivations}

The Ready-made Intervene Design in creation differs from the students' usual design techniques and thinking methods. The research subjects are all elective course students. Students have two roles, namely, the receiver and the sender. The student can independently select a familiar classmate to spark interest, different from the inertial design. The problems faced by students include their lack of interest in the Ready-Made, which prevents them from mastering the process, and their unfamiliarity with the process, which leads to stagnation in creation.

"It is fun at the beginning to get the Ready-Made through 'sending', but I feel indifferent to the received Ready-Made. Leading to cause me to face the stagnation in the process of creation, at the end, I choose another ReadyMade." (S01-Q)

In the past, students used to draw pictures and scenes with direct association and intuition, cut into the theme with excessively abstract words, present the pictures directly with superficial forms, or embellish the works with excessive emotional words when they could not be explained. In terms of the willingness to learn, they used to focus on the technical level, lacking the analysis of the subject matter, the imagination of details, the ability to collect data, and the application of material vocabulary. Therefore, the teaching process provides case sharing, quick question-and-answer games, and group discussions to strengthen the stimulation and learning on the exploration of the visual image, hidden meaning, and material meaning of "ready-made".

\subsection{Scenarios Encourage Students to Develop Creative Thinking}

The question in the 4 comic strips study list is, "How does 'Ready-Made' drift to 
you?". The students were instructed to describe it through drawing. The design stems from the association of experience accumulated by the individual, and students are expected to think wild, like kids, in design thinking to imagine out of reality and present a narrative account. Students face problems like restrictive thinking, reasonable story image, and a lack of imagination. They are afraid of making mistakes due to unreasonable plots and fearful of unrestricted fantasy elements.

" 4 comic strips is a way to stimulate creativity, which is more attractive than texts." (S03-I)

"4 comic strips do not have a direct influence on the later design. It directly extends and associates to the Ready-Made." (S20-I)

"Unsure of the ready-made definition at the beginning, it is easy to confuse and be confused. For me, the process of sharing stories from classmates is also great learning." (S14-I)

The situational imagination is relatively unfamiliar to students with the starting point of the "Ready-Made" itself. Relying on the study list, teachers should perceive students' thinking paths and characteristics to classify their characteristics into creative (meaning) and technical (technology). Creativity-type students have more fun ideas, while technology-type students associate more with daily situations and direct association with appearance.

Based on the perspective of empathy, peer feedback and reviews should be increased. Meanwhile, an interesting Ready-Made is selected and exchanged with a new story as feedback. $9 \%$ of students at the stage considered that it was influential in their creation and improved their learning effect. The teaching process should increase the exploration of the visual perception of "Ready-Made", design positioning, and analysis techniques. Furthermore, it should encourage students to be unconstrained in their imagination and make bold attempts to put forward imaginary mistakes in their cognition.

\subsection{Sketchbook Helps Students to Construct the Context of Creation}

A sketchbook contains the creative process, including the data collection in the previous stage, the record of weekly progress, the feedback and suggestions of the study list, which also includes model making, material research, image record during the experiment, and textual experiment in the later stage.

"Recording in a sketchbook is very helpful for me, and I like it very much. I can clearly write down my ideas, draw drafts, and the context in a sketchbook. It is a complete record and collection of images that I can continuously review." (S04-I)

"My work is quite conceptual, and the sketchbook is very instrumental in organizing the context and my thoughts." (S11-Q)

For the Ready-Made in hand, we can analyze it from the appearance, meaning 
delivery, and media vocabulary, and carry out data extension weekly to support the context of different individuals through the writings of texts, keywords, thoughts on mind maps, experimental records of media, photos or videos and others in weekly production. S22 finds that he is often stuck in the direct association of form. On the other hand, S14 often stops and chooses to change a direction when he finds difficulty coming up with concepts and ideas. He tends to wander at the origin and gets lost. At this stage, the in-group topic analysis should be strengthened, as well as the method of writing and analyzing the text.

Based on the students' narrative, it was found that the lack of clarification of keywords and in-depth integration of the thinking related to the core concepts required teachers' clear guidance and suggestions to avoid the first convergence being too broad, which might have easily led to confusion and unfocused thinking. At this stage, about $38 \%$ of the students considered it highly influential in their creation, which differs from the previous guidance designed to directly cut into the theme and result. Furthermore, students' case sharing in class can encourage learning among peers.

\subsection{Material Experimentation Helps Clarifying Concepts}

Material experimentation can be defined as the challenge to exploration and creation, which focuses on the training of insight and guides to viewing the medium as the prototype in the experiment in a more detailed way as shown in $\mathrm{Ta}$ ble 2 in order to discover designs out of expectations. S17 disassembled the

Table 2. The process of media experimentation.

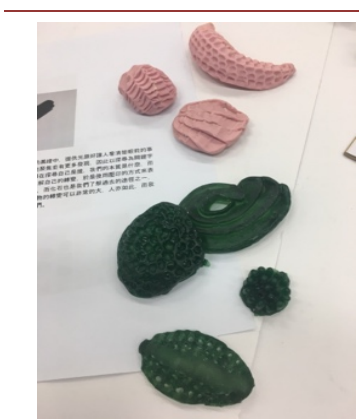

S17 Ready-Made/Flashlight

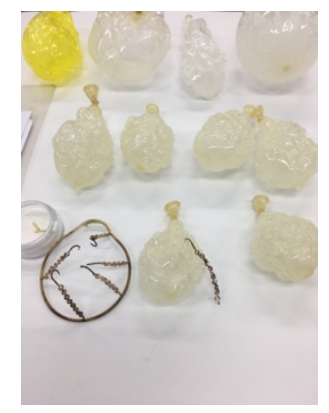

S08 Ready-Made/Balloons

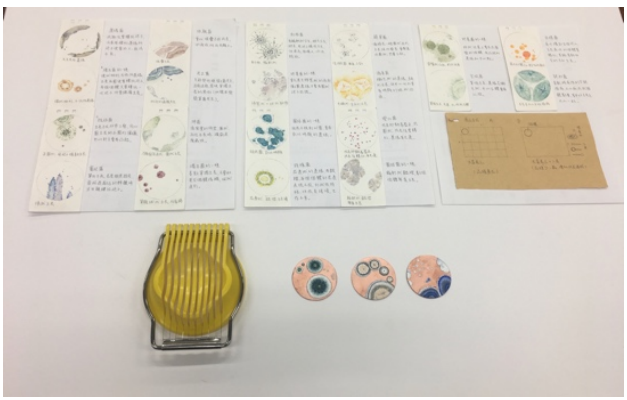

S22 Ready-Made/Egg cutter

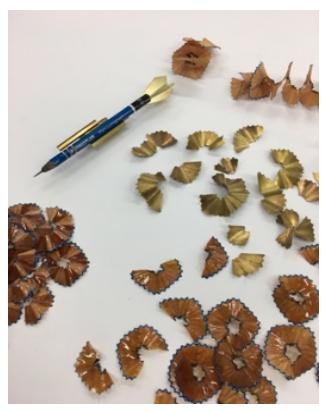

S03 Ready-Made/Pencil

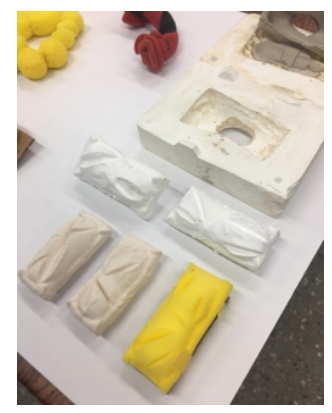

S14 Ready-Made/Sponge

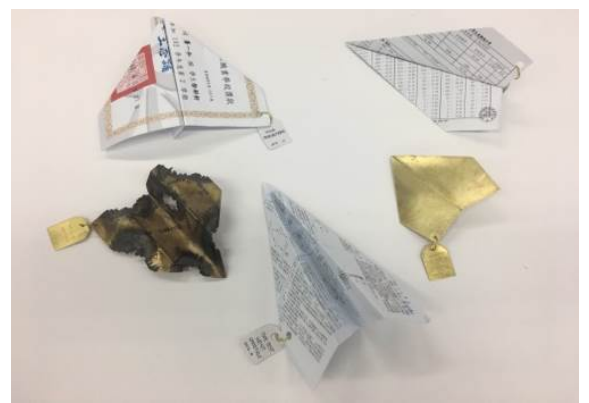

S01 Ready-Made/Paper

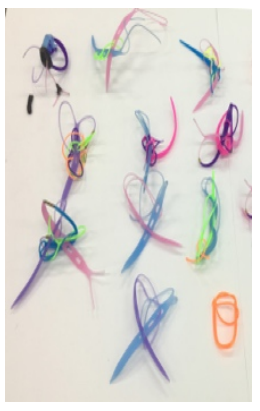

S16 Ready-Made/ Braiding tool

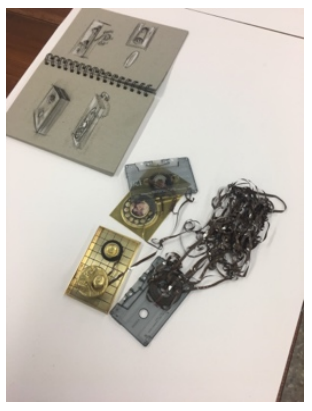

S09 Ready-Made/ Audio tape 
Ready-Made/flashlight, took each part as a tool, and rubbed it on clay to show the texture at different levels, which is of great significance. S16 changed the Ready-Made/hair braiding tool in the media experimentation, which created a different style and color, allowing the design to get rid of the original framework, which is highly beneficial. A few students easily encountered problems like being confused about carrying on or afraid of having zero experience. S01 found that he could not clearly analyze the operation of the media and the symbols of material and come up with an ingenious manner of creating a narrative account, which required the teacher's guidance.

"Material experimentation is more difficult than my past experience, and I found it requires great comprehension of the media and very precise judgment. In the process, I already knew that I could carry on, so I reflected on the method of establishing the con-text to think." (S11-I)

"Material experimentation has greatly inspired me. Due to time constraints, I cannot provide a very good presentation at last. But I found it very interesting to observe the inter-action between the balloon and the epoxy resin during the process, which I can use the concept which reflected by the materials experiment in the future." (S08-I)

"I have used many material combinations in material experimentation and tried various kinds of sponges and destruction, which is the most interesting part. Based on my experiment, I re-verified the text records to find the most related keyword, which I believe different ways should be correlated."

After the first divergent thinking and convergent integration, students could rely on the meaning and concepts carried by Ready-Made. Based on the sketchbook, the students' five senses were re-stimulated by intuition and tactile sensation through a dynamic model, leading to the possibility of self-dialogue and critical reflection.

Through the experience of being in touch with the ready-made object, many surprising results and triggers were found. On the other hand, through the experiment by touching the real object, surprising results and triggers were also found, including the different properties of each material (e.g., plastic, cardboard, spun cloth, magnets, and foam) re-structured by destroying and constructing in the experiment, which came out of shape. At this stage, about 53\% of students had fun during the media experimentation. The Ready-Made is more delicate, which could improve their imagination and present more new possibilities in the experiment process.

\subsection{Integrating Techniques Elevates Students' Works}

The design difference of technology integration in the second convergent design lies in whether the students' selection of craft making technique can conform to the connotative expression of the concept. When techniques are regarded as part of the vocabulary of works, they are not only regarded as a requirement of mak- 
ing process in works, but they also trigger more thinking at different levels. The works include techniques of soldering construction, claw setting design, chemical patina, casting and molding, and enamel firing, which strengthen the focuses of final themes.

Through group conversations, individualized guidance, and expert critiques, individualized core suggestions were given on the works after observing the students' characteristics in the early stage. The final works were published, and the top nine works by viewer preference votes were listed and presented, as shown in Figure 2. For an analysis of the creation types of the said works. In the figure, the solid lines show the correlation between design categories, while the dashed lines show the indirect correlation between technique types.

Through the overall idea exploration of works, integration of technical

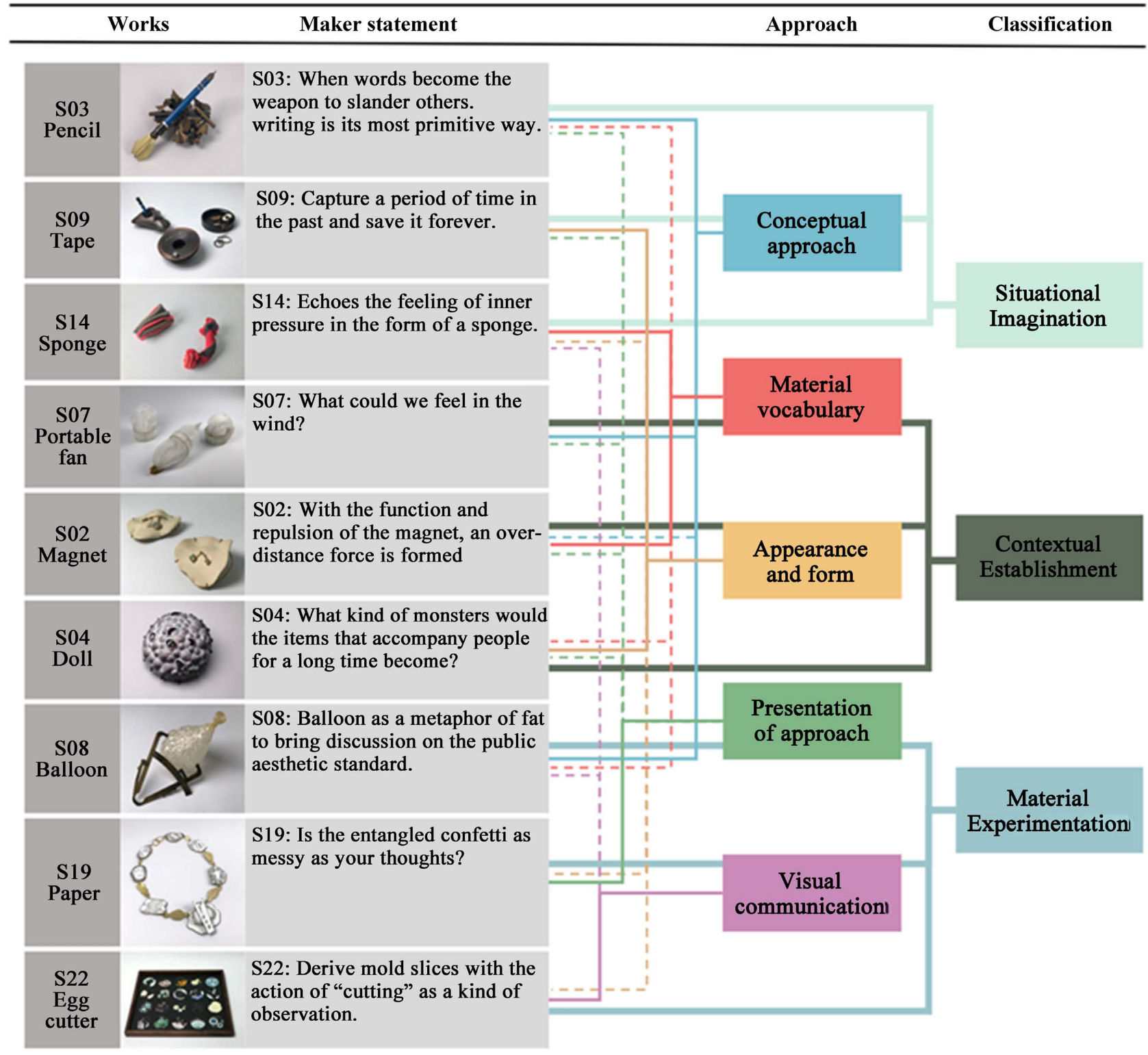

Figure 2. Evaluation and analysis of student works. 
experiments, and overall visual planning of the final exhibition, students can be promoted to further trans-form the design thinking of the three stages of "Discover", "Define" and "Develop" in the double diamond model into works using the process of media experiment, including the stage of work presentation, arrangement of expert comments, and viewing and asking questions by a third person, so that both students and teachers can withdraw from subjective comments and rethink from an objective standpoint.

\subsection{Findings and Analysis}

A comprehensive analysis of the first three stages of design thinking and creation path analysis is shown in Figure 3. The learning result differs for each individual, which can be divided into two major types. Through the process of creation, particularly the Ready-Made, four directions can be summed up, including functional imagination, meaning extraction, formal association, material vocabulary, indirect relation, and other design summary. Based on the learning results from practice-led research, students' works present multiple ways of creative thinking.

The key of the Ready-Made Intervene Design is to break the inertial thinking model. In addition to the above-mentioned four creative results, a few students felt confused with the process and even felt afraid of the unclear orders and unpredictable results that they wanted to give up completing the mission derived from Ready-Made. $63 \%$ of the students believed that the design of the class should keep the identifiability of Ready-Made, and 35\% of students chose to

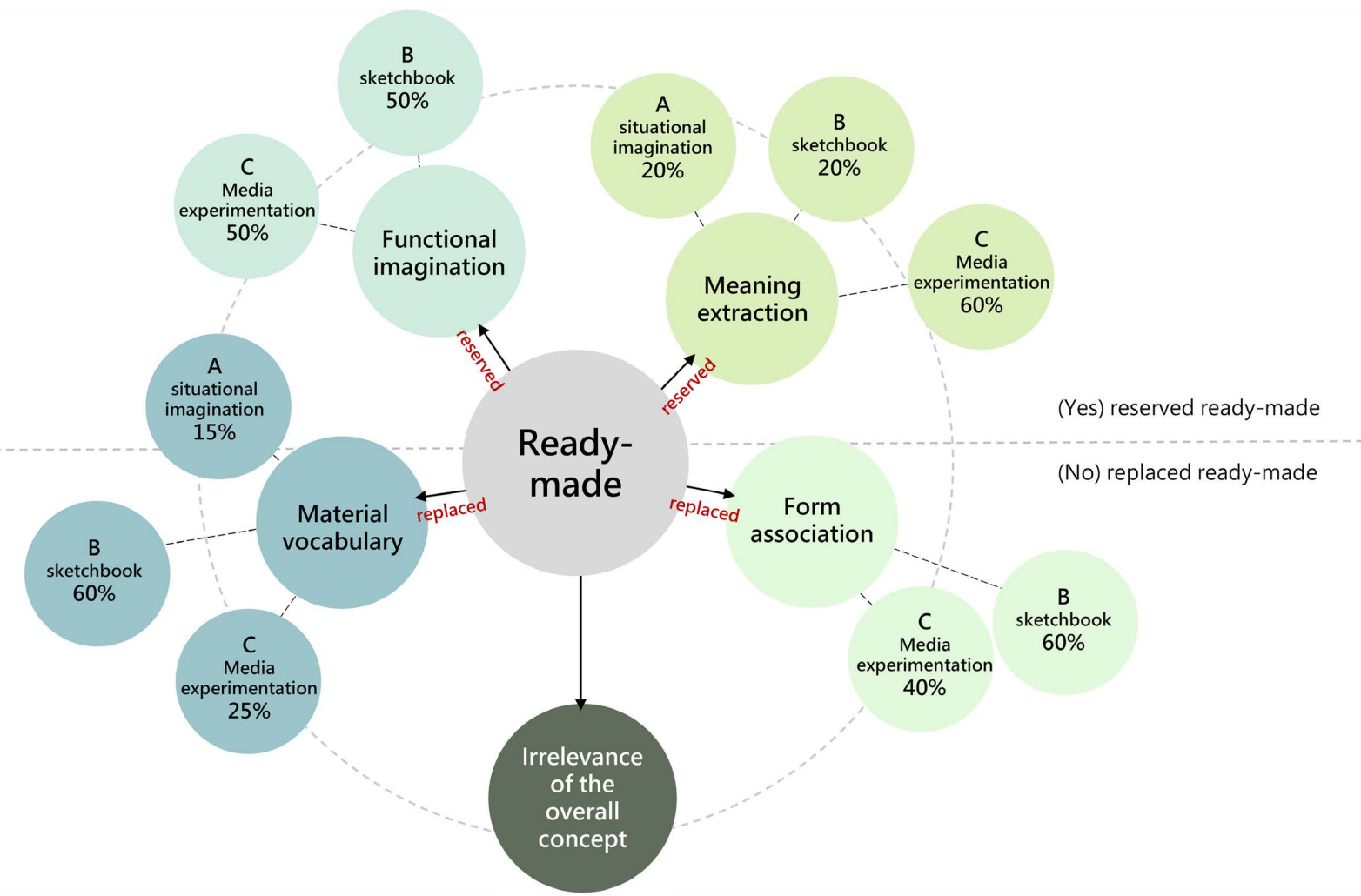

Figure 3. Type of presentation of the Ready-Made works of students (summarized by this research). 
transform the concept and left no reservations of the Ready-Made itself. Meanwhile, $2 \%$ of students could not understand that the topic is irrelevant to the development of Ready-Made. The teacher should strengthen the research analysis associated with the context to guide students and clarify a specific theme or core.

The questionnaire includes a self-learning questionnaire, achievement and evaluation, and a viewer questionnaire. For example, "which part of the design of intuitive expression works will affect identity?" is a multiple-choice question, including the assessments of "Appearance and Form", "Concept Application", "Color Communication", "Technique Presentation", and "Material Vocabulary", as shown in Figure 4 and Figure 5 to explore the difference between subjective analysis (creator) and objective consciousness (viewer).

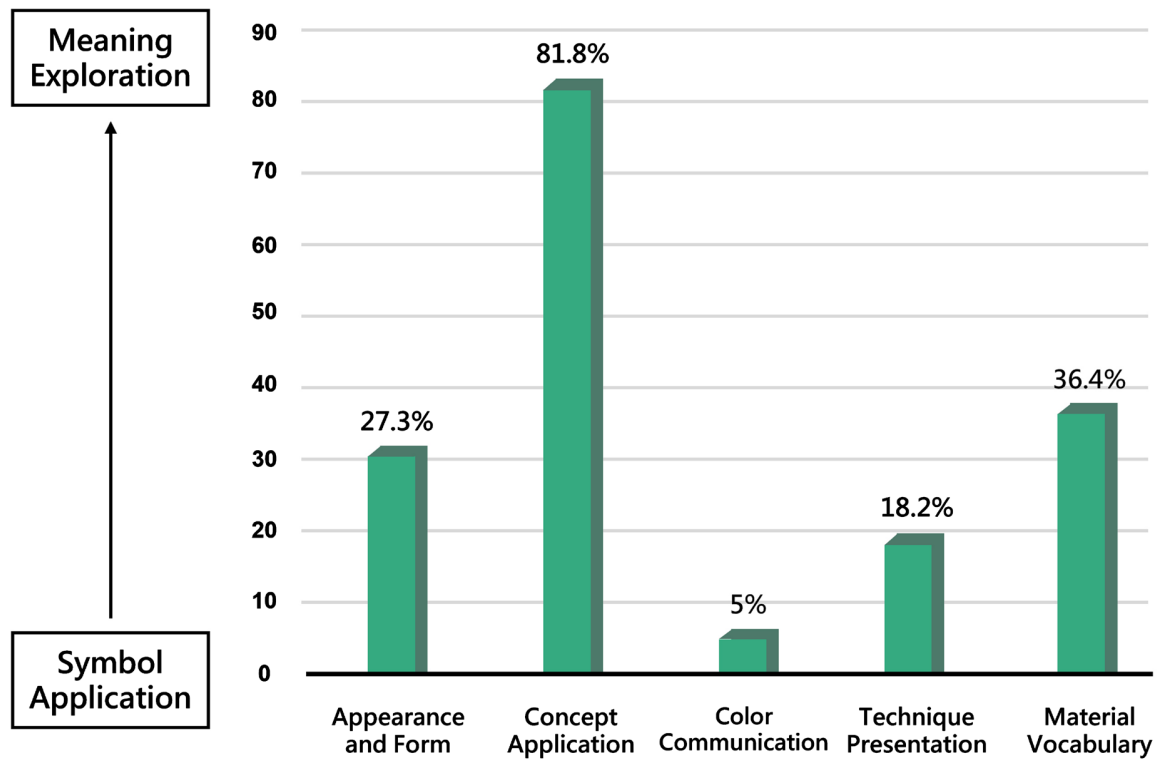

Figure 4. The perspective of the creator.

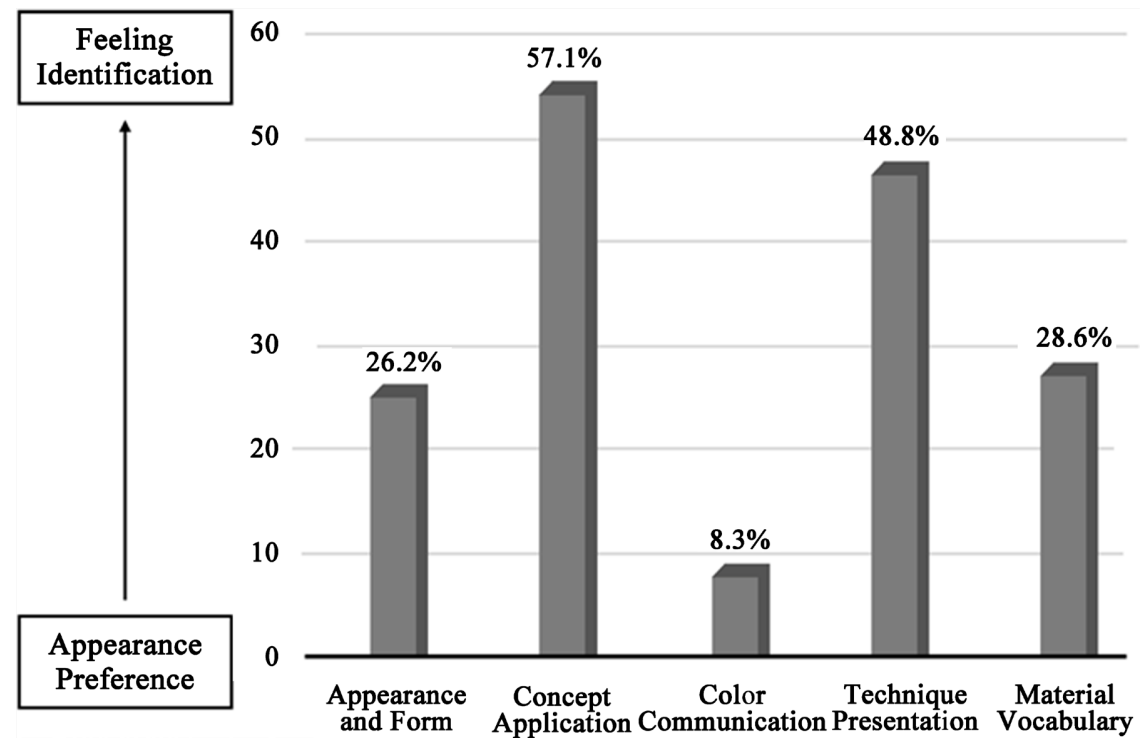

Figure 5. The perspective of the viewer. 
After evaluating the overall questionnaire, 113 valid questionnaires were collected, including questionnaires of 23 students who took the course. 90 people visited the exhibition, all from the field of art and design. In Figure 4, based on students' self-evaluation, students should reflect on the process of creation from the perspective of creators, focusing on concept application $>$ material, vocabulary $>$ appearance, and form $>$ technique presentation $>$ color communication, to find out the design method and effectively improve the way students use inertial techniques (technique presentation) and form (appearance and form) to set up the theme.

The randomness and unexpectedness of ready-made intervene design, the process guidance of playfulness, and the learning gap lie in students' participation in the course and their expectations for exploring unknown fields. Sketchbook and material experimentation can strengthen the breadth and depth of the content and understand deeper the meaning of material vocabulary. The learning gap lies in the degree of students' enthusiasm in the class, as well as the degree of acceptance of feedback from peers, classmates, and teachers. The results show that concept application $>$ technique, presentation $>$ material, vocabulary $>$ appearance and form $>$ color communication from the viewer's perspective.

The evaluation and analysis of the common points show that the concept has a significant appeal to the viewer, as shown in Figure 5. On the other hand, technology demonstration, including the expressiveness of craftsmanship, reflects that metalsmithing design is significantly important to the viewer's role. The meaning of Ready-Made is used for occasional definition, substitution, reorganization, extension, replacement, and other statements that occurred during the experiment, which got rid of the one-way thinking. In the viewers' votes and suggestions, the objectivity and superiority of students' evaluation of their own works can be in-creased, assuming that one can learn by experience to accept the challenge effectively when facing the question and practical operation of the design process in the future.

\section{Teaching Reflection and Enlightenment}

Based on previous teaching experience, we never stop to think about the role of teachers and the problem awareness of students in East metalsmithing education. The creative process lacks the learning of creative connection because students tend to follow instructions from teachers. In the craft field, artistic and design works are created under different creative methods. However, revising teaching methods can help teach a design attitude and find suitable methods for guiding students to create. In this study, a creative design thinking model was developed through the double diamond model process. The teaching roles and reflections are described as follows:

\subsection{Difficulties in Teaching Practice}

During the teaching process, when students encountered a learning mode for the 
first time, such as asking questions, they felt confused and even gave up the conversation halfway. The discussion can be performed from these aspects: 1) the vague definition of Ready-Made leads to the interruption of interpretation and communication in the later stage; 2) according to the situational imagination, through four panels comic, including the design of the study list, peer review, and operational story feedback, without wild imagination, students tended to describe the role of Ready-Made as presented in daily life; 3 ) in material experimentation, students were prone to feel difficult because they are not only unfamiliar with or inexperienced at experimental learning, fear of deconstructing the material, but also unwilling to deeply reflect on themselves, expand their knowledge base, or even afraid of communication, debate, and criticism from their classmates, which often led to giving up in this unit.

\subsection{Teaching Analysis and Observations on Student Characteristics}

1) Have a high willingness to learn and a positive attitude, full of expectations for unknown results and challenges, and show an upward influence on learning ability in the team. 2) Students who tend to make plans will find the difference and learning between data analysis and creative mind through the sketchbook. Correct judgment and selection of keywords with creative and diverse thinking expansion will be conducive to mutual learning among peers. 3) Students who are good at experiments will share their methods and process of operational practice, and the appropriate narrative of ideas can stimulate practical application in the group. 4) Students who are good at narratives can inspire students to think and speak through storytelling. It can arouse more resonance and active publication among students.

In the analysis of the regression research process design as shown in Figure 6, most students can follow the teacher's teaching process, while some students do not understand it, thereby affecting the development of the three stages. Therefore, remedial teaching methods are proposed as follows: 1) Situational imagination: to guide students to appropriately plot narratives or wild fabrications. 2) Sketchbook: redefinition and interpretation of words can re-examine the links of relevant data texts and clarify and explore problems. 3) Media experimentation: to guide students in destroying or recombining materials by thinking about the meaning or symbolic meaning of ready-made objects. 4) Technology integration: the integration of thinking and the application of technology do not mainly consider the presentation of techniques but rather emphasize whether the link between concept and design thinking can resonate with viewers.

Through the ready-made intervene design, ready-made objects can convey more image definition or can be redefined to translate the meaning, attaching importance to the resonance of perceptual connection in different stages. Teachers should master the three principles of the creative process: 1) Do not allow students to think in their customary ways, but rather design the course with games; 2) Do not provide specific answers, but only provide interactive questions and 


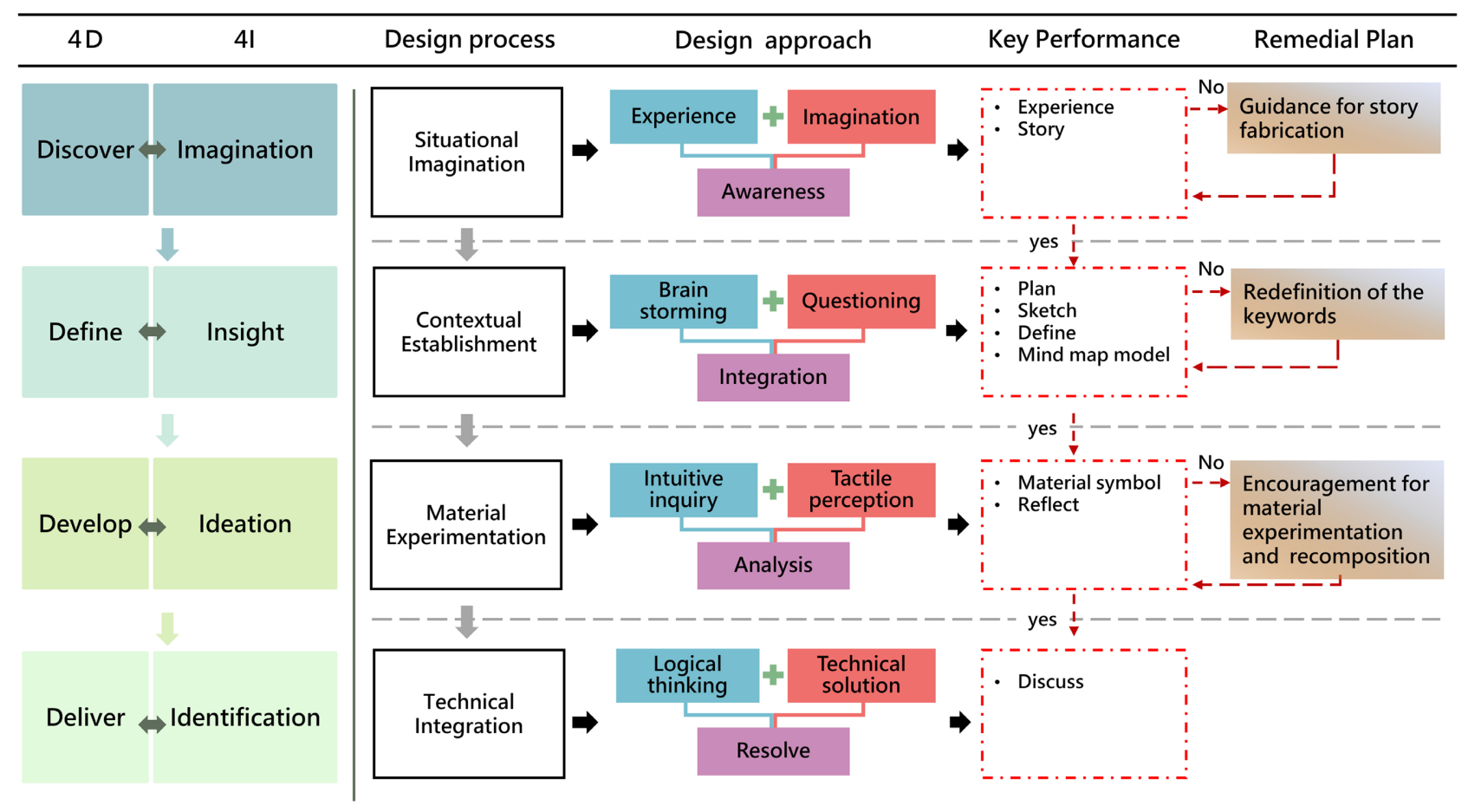

Figure 6. Process design of creative thinking.

answers; 3) Do not care about the final result, but care about the unpredictability and model development in media experimentation and attach importance to the dialogue and process-sharing with peers. Further, teachers should master the principles of design evaluation, requiring students not to rely on or copy network information and refuse direct collage in design thinking. The exhibition of works includes two sections: process-related thinking path and completed works, which are regarded as a complete presentation. The process of sharing is more important than the learning process of the works.

According to the data from the analysis and interviews, the purpose of this research is to intervene ready-made objects and the four stages of the design process to effectively enhance creative thinking and establish self-core competency and their abilities. The researchers conducted the study via class observation, interviews, and questionnaires and concluded the following results. The findings showed that incorporating double diamond learning model, two divergent thinking phases, learning contexts that include Situational Imagination and exploratory media experiments all encourage student cooperation and their learning skills and enhance their problem-solving skills. The finding supports Vande Zande's (2007) and Vygotsky's (2003) points of view that group sharing, listening to other people's learning experiences, and conscious and game-like thinking help cultivate the foundation of creativity. The two stages of convergent thinking can be used to improve students' language and logic: students learn through implementing their skills finding connections between their reflections and the design. The concept echoes Torp and Sage's (1998) point of view that students' previous learning experiences and interactions with their peers and 
teachers help establish their self-cognitive learning process. Students' awareness and creativity that emerge from the learning process further form an essential foundation in creative education.

\section{Conclusion}

The guidance of the "ready-made" intervene design is better than the traditional teaching model of asking and answering, which forms a clear indication. The method of non-self-selected questions is introduced into the course to induce innovative thinking, aiming at breaking the creative mode of students' habitual thinking. In the process of students' first attempt, teachers play the role of just posing questions or focusing on the design situation. In addition to asking questions and listening, they should take into account students' personality traits and learning comprehension and give appropriate directions for discussion according to the degree of their understanding. Whether teachers' own opinions will interfere too much and affect students' autonomy is also a matter of concern for teachers from time to time. As for the role of students, in the process of psychological adjustment from passive learning to autonomous response, they must honestly face the shortcomings of self-concept and adjust their attitude towards learning.

This study has several limitations. Firstly, the teaching process and the use of ready-made objects are not a fixed structure. Therefore, the effectiveness of the teaching results will depend on the instructional design and the teachers' specialties. The second limitation was that the research participants (students) had learned about metalsmithing techniques. Thus, beginners of metalsmithing might have different reflections and results from this study. The challenges and suggestions for analyzing students' characteristics might help improve the implementation process. In addition, learners use "ready-made objects" as tools to discover realistic perception, and mental thinking training is applicable to the related field of design thinking. Moreover, the incorporation of the creative thinking mode can effectively improve students' creative thinking and strengthen their " $4 \mathrm{I}$ " ability (i.e., Imagination, Insight, Ideation, and Identification) to practice the ripple effect produced by the interaction of $4 \mathrm{D}-4 \mathrm{I}$. It is important to note that the design process and the tools are not a fixed structure; therefore, different results might be found in different teaching fields and classes. In the future, the research team will evaluate how ready-made objects' textures are a medium for design innovation. Moreover, the research team hopes to strengthen a research methodology that emphasizes creative thinking in the field of art and design to 1) cultivate student' team cooperation skills, 2) promote interdisciplinary collaboration, and 3) enhance the development of innovative education.

\section{Conflicts of Interest}

The authors declare no conflicts of interest regarding the publication of this paper. 


\section{References}

Baer, J. (2021). Domain Specificity and the Limits of Creativity Theory. Journal of Creative Behavior, 46, 16-29. https://doi.org/10.1002/jocb.002

Bi, W., Lyu, Y., Cao, J., \& Lin, R. (2021). From Usability to Pleasure: A Case Study of Difference in Users' Preference. Journal for Engineering, 13, 448-462.

https://doi.org/10.4236/eng.2021.138032

Brown, T. (2008). Design Thinking. Harvard Business Review, 86, 84-92.

Chen, W., \& He, Z. (2013). The Analysis of the Influence and Inspiration of the Bauhaus on Contemporary Design and Education. Journal for Engineering, 5, 322-328. https://doi.org/10.4236/eng.2013.54044

Collins, R., \& Stevenson, L. (2004). Inspiring Imagination-Education and Learning: The University Experience in the Regional Development Cocktail.

https://ro.uow.edu.au/cgi/viewcontent.cgi?referer=https://scholar.google.com.tw/\&http $\underline{\text { sredir }=1 \& \text { article }=1008 \& \text { context }=\text { asdpapers }}$

Cropley, A. (2006). In Praise of Convergent Thinking. Creativity Research Journal, 18, 391-404. https://doi.org/10.1207/s15326934crj1803 13

Cropley, A., \& Cropley, D. (2008). Resolving the Paradoxes of Creativity: An Extended Phase Model Creativity. Cambridge Journal of Education, 38, 355-373. https://doi.org/10.1080/03057640802286871

Dennis, H. (2019). The New Double Diamond Design Process Is Here. Design Leadership Notebook.

https://medium.com/design-leadership-notebook/the-new-double-diamond-design-pr ocess-7c8f12d7945e

Design Council. What Is the Framework for Innovation? Design Council's Evolved Double Diamond.

https://www.designcouncil.org.uk/news-opinion/what-framework-innovation-design-c ouncils-evolved-double-diamond

Eggink, W. (2010). The Reinvention of the Ready Made. In J. Gregory, K. Sato, \& P. Desmet (Eds.), Proceedings of the 7th Design and Emotion Conference 2010 (pp. 1-23). IIT Institute of Design.

Eggink, W. (2018). Rules of Unruly Design: Lessons from the History of Anti-Modernist Aesthetics. University of Twente.

Freitas, N. (2007). Activating a Research Context in Art and Design Practice. International Journal for the Scholarship of Teaching and Learning, 1, 1-15. https://doi.org/10.20429/ijsotl.2007.010214

Gray, C. (1996). Inquiry through Practice: Developing Appropriate Research Strategies. http://carolegray.net/Papers\%20PDFs/ngnm.pdf

Habib, M. K., Nagata, F., \& Watanabe, K. (2021). Mechatronics: Experiential Learning and the Stimulation of Thinking Skills. Education Sciences, 11, 46. https://doi.org/10.3390/educsci11020046

Haseman, B. (2007). Rupture and Recognition: Identifying the Performative Research Paradigm. In E. J. Barrett, \& B. R. Bolt (Ed.), Practice as Research: Approaches to Creative Arts Inquiry (pp. 147-157). I. B. Tauris. https://doi.org/10.5040/9780755604104.ch-011

Hekkert, P., Snelders, D., \& Van Wieringen, P. C. (2003). "Most Advanced, Yet Acceptable": Typicality and Novelty as Joint Predictors of Aesthetic Preference in Industrial Design. British Journal of Psychology, 94, 111-124.

https://doi.org/10.1348/000712603762842147 
Ho, W. L., Lee, C. L., \& Chen, C. H. (2013). A Case Study on Teaching Art and Design Practice-Led Research in University: Integrating Creation with Theory and Writing. Art Education, 26, 1-32.

Hoff, E. V. (2013). The Relationship between Pretend Play and Creativity. In M. Taylor (Ed.), The Oxford Handbook of the Development of Imagination (pp. 403-416). Oxford University Press. https://doi.org/10.1093/oxfordhb/9780195395761.013.0026

Hu, S. F. (2013) Ready-Made Representation in Contemporary Art Jewelry. Beauty and Times: Part I, 5, 112-114.

Lee, P. L. (2005). Ready-Made to Modern Design Idea Impact and Reconsidering. Journal of National Normal University, 50, 91-103.

Lin, M. H., Lin, Y. S., \& Wang, C. Y. (2019). Investigating the Design Logic of the Readymade Design from Semiotics Viewpoint. Journal of Design, 24, 1-2.

Lu, G. S. (1996). The English-Chinese Dictionary. Dong Hua Ltd.

Lubart, T. I. (2021). Models of the Creative Process: Past, Present and Future. Creativity Research Journal, 13, 295-308. https://doi.org/10.1207/S15326934CRJ1334 07

Plucker, J. A. (1998). Beware of Simple Conclusions: The Case for Content Generality of Creativity. Creativity Research Journal, 11, 179-182.

https://doi.org/10.1207/s15326934cri1102 8

Rafiq, E. (2021). The Double Diamond Design Thinking Process and How to Use It. Designorate.

https://www.designorate.com/the-double-diamond-design-thinking-process-and-how$\underline{\text { to-use-it }}$

Rosen, Y., Stoeffler, K., \& Simmering, V. (2020). Imagine: Design for Creative Thinking, Learning, and Assessment in Schools. Journal of Intelligence, $8,16$.

https://doi.org/10.3390/jintelligence8020016

Runco, M. A., \& Acar, S. (2021). Divergent Thinking as an Indicator of Creative Potential. Creativity Research Journal, 24, 66-75. https://doi.org/10.1080/10400419.2012.652929

Sullivan, G. (2009). Making Space: The Purpose and Place of Practice-Led Research. In H. Smith (Ed.), Practice-Led Research, Research-Led Practice in the Creative Arts (pp. 41-65). Edinburgh University Press.

Torp, L., \& Sage, S. (1998). Problems as Possibilities: Problem-Based Learning for K-12 Education (5th ed.). Association for Supervision and Curriculum Development.

Vande Zande, R. (2007). Design Education as Community Outreach and Interdisciplinary Study. Journal for Learning through the Arts, 3, 4. https://doi.org/10.21977/D93110053

Vygotsky, L. S. (2003). Imagination and Creativity in Childhood. Journal of Russian and East European Psychology, 42, 7-97. https://doi.org/10.1080/10610405.2004.11059210

Ward, T. B., Smith, S. M., \& Vaid, J. (1997). Conceptual Structures and Processes in Creative Thought. In T. B. Ward, S. M. Smith, \& J. Vaid (Eds.), Creative Thought: An Investigation of Conceptual Structures and Processes (pp. 1-27). American Psychological Association. https://doi.org/10.1037/10227-001

Wolfram, E. (1992). History of Collage. Yuan Liou Ltd.

Woolley, J. D., Bunce, L., \& Boerger, E. A. (2020). Relations between Imagination and Creativity. In Creativity and the Wandering Mind (pp. 181-203). Academic Press. https://doi.org/10.1016/B978-0-12-816400-6.00008-0

Wu, K. C., Su, Y. L., \& Tsau, S. Y. (2013). Explore the Teaching Models for Design Studio by the Thinking Stimulation of Imagination. Journal of Architecture, 83, 19-35.

Zamora-Polo, F., Corrales-Serrano, M., Sánchez-Martín, J., \& Espejo-Antúnez, L. (2019). 
Nonscientific University Students Training in General Science Using an Active-Learning Merged Pedagogy: Gamification in a Flipped Classroom. Education Sciences, 9, 297. https://doi.org/10.3390/educsci9040297

Zedelius, C., \& Schooler, J. (2016). The Richness of Inner Experience: Relating Styles of Daydreaming to Creative Processes. Frontiers in Psychology, 6, Article No. 2063. https://doi.org/10.3389/fpsyg.2015.02063 